Critical Studies in Improvisation / Études critiques en improvisation, Vol. 14, Nos. 2-3

\title{
What the World Needs Now is Jazz
}

\section{Monika Herzig}

\section{Introduction}

On March 15, 2020 my group Sheroes took the stage at the Keystone Korner in Baltimore, a venue modelled after the famed California Keystone Korner club. What was supposed to be the centerpiece of a three-week CD release tour from the Midwest to the East Coast ended up being the last performance for the group, the last open night for the club, and the last time I saw my bandmates in person. With all of our international tours cancelled, all teaching moved online, all of us were confined to our homes, and most income was suspended indefinitely.

Improvisation-a process in which we as jazz musicians train and engage on a regular basisnow became a life skill. Everyone now had to make decisions regarding how they would move towards a sustainable future in an uncertain environment, with few ways to make predictions and set goals. In the entrepreneurship literature, this challenge of making decisions and shaping the future based on available means and techniques is defined as "effectual entrepreneurship" (Sarasvathy 1), and it is one of the main ingredients of design thinking. Engaging in effectual entrepreneurship takes a growth mindset, defined as the willingness to engage in a continuous cycle of testing ideas, experimenting, learning, and refining strategies-a process to which improvisers are especially attuned as they engage in similar cycles as part of their craft.

One art form that is rooted in on-stage improvisation and collaboration is jazz. The interactions that occur during a jazz performance and/or jam session have been studied extensively as a model for entrepreneurship, specifically understanding the process of improvisation as a method for making decisions in uncertain situations (Barrett 283; Diasio 1; Eisenhardt 251; Hatch 3; Kamoche and Kunha 735; Lewin 539; Walzer and Salcher 67; Weick 543; Zack 227). Such improvisational activity in organizations and groups during crisis features three key ingredients: it occurs during action; it is impromptu; and it is deliberate (Moorman and Miner 698). Duxbury (22) acknowledges that lessons may be drawn from art forms that engage regularly in improvisational activities. Furthermore, studies by Limb and Braun provide evidence that certain parts of the brain are activated during improvisational tasks and that jazz musicians train the activation process towards achieving higher improvisational skill levels.

Using a seven-factor model of the jazz jam session, developed by Herzig and Baker (184) and transferred to organizations by Belitski and Herzig (506), the research team of Vera, Nemanich, Velez-Castrillon, and Werner were able to demonstrate the influence of key factors on the improvisational capacities of R\&D (research and development) teams in organizations (Vera et al. 1984). The seven factors of Herzig and Baker's model are: 1) individual competence and knowledge of the field; 2) practicing improvisation as the ability to overcome self-consciousness; 3 ) establishing a mentoring system and role models; 4) democracy and collaboration; 5) leaders and side-people; 6) community support; and 7) continuous evaluation systems. The influence of these factors is apparent through the innovative techniques of the musicians documented in this study.

While the world struggles with the impact of the worldwide pandemic caused by the outbreak of COVID-19, I argue that the adaptations and strategies developed in the jazz community can provide valuable cues towards the shape of things to come. As mentioned earlier, the improvisational training of jazz musicians supports a growth mindset facilitating the process of effectual entrepreneurship (Sarasvathy 1), meaning the cycle of ideation, experimentation, 
refinement, and implementation that creates sustainable solutions from limited resources. This process is often compared to cooking a meal using ingredients available in the refrigerator, rather than following a recipe and acquiring needed ingredients. Various solutions and options have been developed across musical genres and art forms during the pandemic, but the intimate and exploratory nature of jazz in particular allows for the grassroots experimentation and interaction essential for effectual entrepreneurship. Through various case studies, survey data, and interviews, this essay analyzes effectual entrepreneurship in the jazz world in response to COVID-19 and envisions how the future economy and arts sector puzzle will take shape. While everyone is speculating about what the future will look like, improvising creators with a growth mindset are designing and shaping new models right in front of our eyes.

\section{Method}

In order to pinpoint the entrepreneurial directions taken after the COVID-19 crisis began by a population with a high level of improvisational training, I gathered data in the form of a survey for jazz musicians (self-identified) with 219 international participants recruited through email blasts, social network posts, and personal contacts. The survey data was collected throughout June 2020.

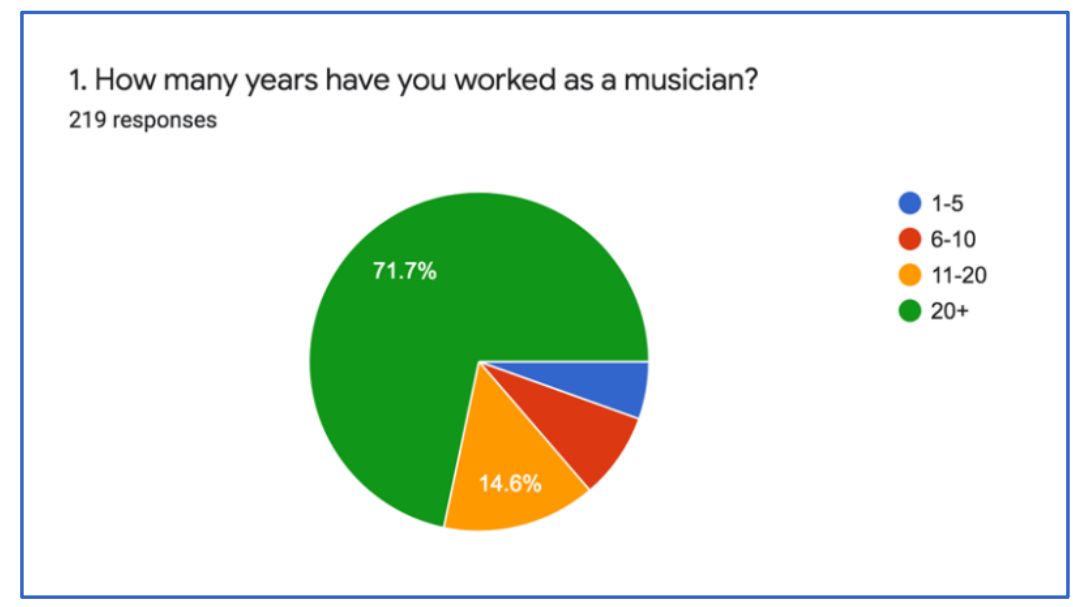

Table 1: Years of Improvisational Experience.

The majority of participants indicated more than twenty years of experience as performing jazz musicians, thus providing a highly trained pool of informants in accordance with the first factor of the jazz jam session model-individual competence and knowledge of the field. Instrument distribution was 52 (23.7\%) woodwinds, 45 (20.5\%) piano/keyboard/mallets, 41 (18.7\%) brass, $29(13.2 \%)$ bass, 23 (10.5\%) drums, 22 (10\%) guitar, 20 (9.2\%) vocals, 4 (1.9\%) strings, and 10 $(4.6 \%)$ indicating composition/electronics/arranging, with several choosing multiple categories. In addition, interviews were conducted with a handful of prominent jazz musicians and educators based in Miami, Los Angeles, Durham, and New York, as well as Karlsruhe, Germany. Further documentation was collected from recently published news items, interviews, and events.

In order to pinpoint pandemic-related adaptions, the survey captured information on pre-COVID income streams and shifts in income and engagement in those areas since March 2020. The respondents were asked to report on the following income stream categories: Teaching, Touring/Live Performance, Studio/Recording, Composition/Arranging, and Other music-related income streams. In addition, they reported on the type and extent of engagement/revenue in 
livestreaming, online teaching, home recording, virtual collaborations, composing/arranging, and other possible categories. Furthermore, information was gathered on new equipment acquisitions, plans to implement new skills and new equipment in their future work, and commentary on the impact of the pandemic on their personal careers and on jazz as an art form.

The income categories were based on the study of revenue streams for musicians conducted by the Future of Music Coalition in 2013, which included two detailed case studies for a jazz bandleader and a jazz side-person (DiCola). Results indicated that the main income streams for jazz musicians traditionally consist of live performance, teaching/workshops, side-person work, and composing. Overall, the findings of the study indicated that jazz musicians have higher education levels than musicians in other musical genres; often play many different roles; usually have less income than classical musicians; and are comfortable using technology for creation, collaboration, promotion, distribution, and fan cultivation (DiCola).

\section{Income Streams and New Ventures}

The goal of the survey and interviews was to identify changes in income streams and musical ventures since the March 2020 lockdown, as well as to collect reflections and commentary on the pandemic's impact. With social distancing orders and the closure of schools, colleges, businesses, and public venues worldwide, a wave of performance cancellations hit the art world generally. All engagements in public venues and festivals were suspended indefinitely. In addition, schools and colleges moved to online teaching, and teaching studios suspended or limited their operations. Beyond loss of income, jazz musicians dealt with the loss of personal contact with listeners and students, loss of access to fellow musicians and band members, loss of industry support, and loss of traditional career pathways.

\section{My momentum for building a career came to a full stop as a musician.}

(Russ Spiegel, guitarist. Interview with the author, June 30, 2020)

As documented in Tables 2 and 3, teaching and touring/performance were the main income streams for survey respondents prior to March 2020. The lockdown had the most financial impact on the touring/performance revenue, as all travel was suspended and all venues closed.

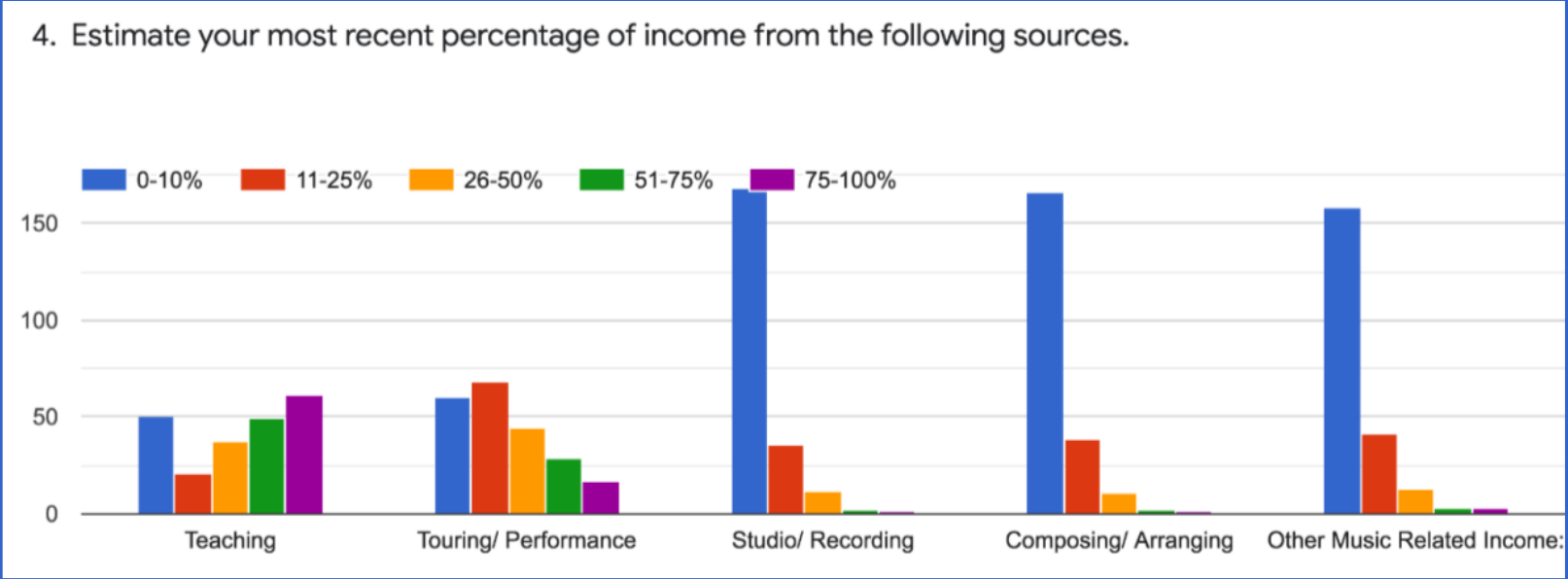

Table 2: Income Stream Distribution Before COVID-19. 


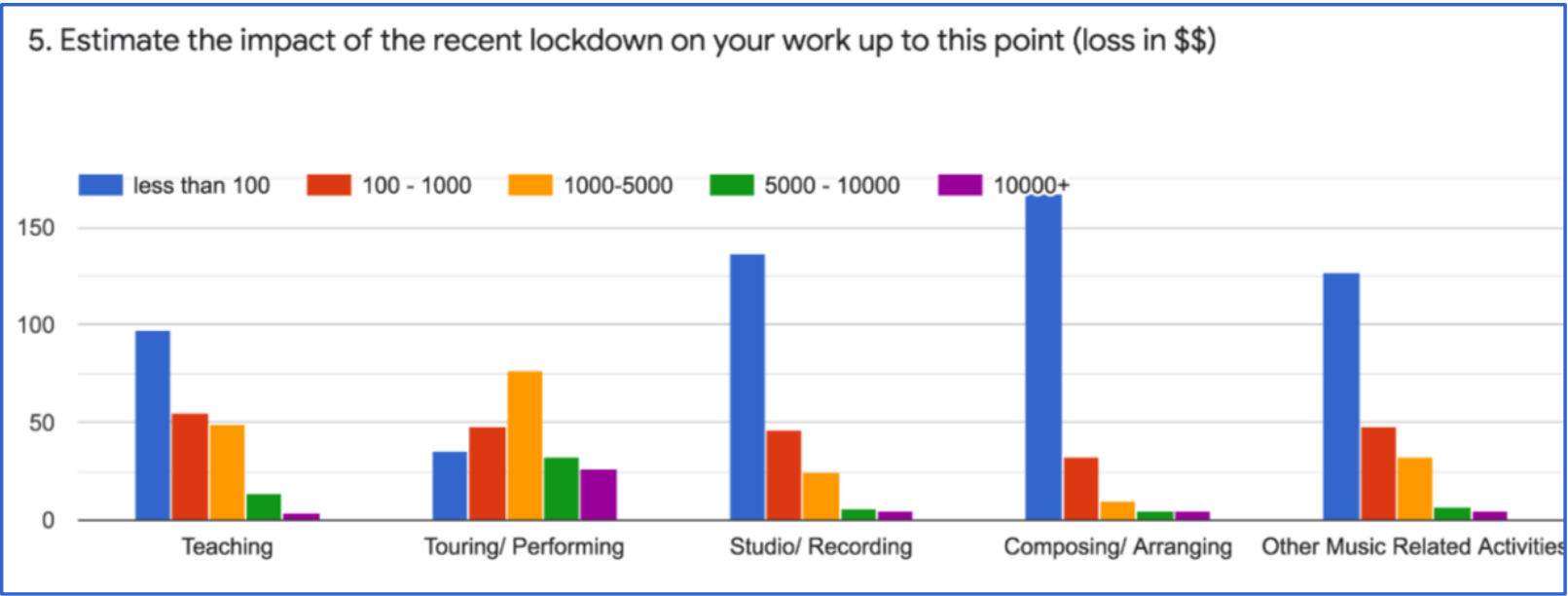

Table 3: Estimated Income Loss Due to COVID-19 Cancellations (in USD).

The loss of touring activity also had a direct impact on music and merchandise sales. Russ Spiegel indicated that the inability to interact with live audiences resulted in a loss of not only performance income, but also in diminished sales of music and merchandise. The rise of subscription services and streaming has diminished income from physical sales greatly, with most merchandise sales taking place at live performances. This trend was documented in the most recent Nielsen mid-year sales report, which indicated a large drop in sales numbers of physical albums, while streaming activity continued to increase. With an average payout of $\$ 0.0032$ per stream ${ }^{1}$ compared to a $\$ 10$ album sale, the increase in streaming is clearly not a substitute for physical sales income. Hence, the traditional performance career path of building a fan community through live performances that would result in product sales was placed on hold.

\begin{tabular}{|l|l|l|l|}
\hline PRE-/POST-COVID-19 ANALYSIS: 2020 & VS. SAME PERIOD 2019 \\
\hline & $\begin{array}{l}\text { YEAR TO DATE } \\
\text { THROUG } \\
\text { MARCH 12 }\end{array}$ & MARCH 13-JULY 2 & $\begin{array}{l}\text { TOTAL 2020 } \\
\text { YEAR TO DATE }\end{array}$ \\
\hline Total Audio Activity & $+14.6 \%$ & $+6.2 \%$ & $+9.4 \%$ \\
\hline On-Demand Audio Streaming & $+20.4 \%$ & $+13.8 \%$ & $+16.2 \%$ \\
\hline Total Album Sales & $-6.7 \%$ & $-25.2 \%$ & $-18.1 \%$ \\
\hline Physical Albums & $+4.6 \%$ & $-35.4 \%$ & $-20.3 \%$ \\
\hline Digital Album & $-24.6 \%$ & $-7.3 \%$ & $-14.3 \%$ \\
\hline Digital Song Sales & $-26.4 \%$ & $-21.2 \%$ & $-23.3 \%$ \\
\hline
\end{tabular}

Nielsen mid-year report, 2020.

Then I started looking around and I saw that you had folks like Cécile McLorin Salvant and Emmet Cohen and Fred Hersch putting things out there.

(Tamir Hendelman. Interview with the author, July 1, 2020) 
As discussed earlier, the jazz model has been a frequent metaphor for entrepreneurship and emergency management. Mendonça and Wallace, for example, analyze the actions of improvisers as a cognitive model for emergency response (548). Improvised solutions producing new models of creation and interaction rapidly manifested themselves as the jazz community found itself in crisis mode addressing diminished performance income and challenges to career development.

Many artists turned to livestreaming. In fact, 57 survey respondents (26\%) indicated "going live" at least once a week, with others conducting daily broadcasts in the form of livestreams and interactive discussions. While the platforms and models for streaming concerts and other programs are extensive, finding the ideal setting to transmit, gather support, and reach audiences can be a daunting task. Options for sharing include video streaming, audio streaming, or simulcasting across several platforms. Sharing the music-making process, for instance, can be done via a livestream that captures video and audio, over a platform such as Facebook, Instagram, or YouTube. Alternately, to avoid visual influences, sharing may be done in the form of an audio podcast or audio recording. With the help of various software options, sharing can even take place over several platforms simultaneously, in order to reach listeners who might not be Facebook or Instagram users, for example. The financial models can be categorized into free (e.g., Zoom, Instagram, Facebook, Linkedln, YouTube Live, Google Hangouts); free-to-play (including an in-app voluntary payment option, e.g., Twitch, YouNow, Mixer, Sessions); and ticketed/paywalled (e.g., Run the World, Stagelt, Patreon, Veeps, Crowdcast). Deciding on which platform to use requires weighing the options of providing free events in order to reach as many listeners as possible, asking for voluntary contributions, asking listeners to buy tickets for a members-only broadcast, or any combination of these. And, as a side effect of the recent uptick in demand, many more platforms are in development.

Furthermore, the presentational style and purpose of livestreams varies considerably, from stage settings with high quality cameras and audio equipment to casual living room sets broadcast via a personal phone; from concerts mixed with commentary to panel discussions; from master classes to webinars.

Below are a few examples from the jazz world of experimental responses to the loss of traditional engagement options:

1) Using his personal phone, 23-time Grammy winner, 65-time nominee Chick Corea went live on Facebook from his home studio for 34 consecutive days to practice various pieces with interactive commentary. Each free livestream averaged around 6,000 views. Eventually, he launched the Chick Corea Academy as a $\$ 300 /$ year subscription option, offering access to unique, subscriber-only content. Various excerpts from the Facebook streams became promotional videos. The massive engagement during the initial 34 days of free streams cultivated a dedicated pool of potential subscribers once the academy launched.

Corea's strategy is an example of transitioning from the free to the paywalled model. Moreover, it showcased a jazz superstar in an intimate setting - alone, livestreaming with his own phone in his personal practice studio. In the past, audiences only had access to Chick Corea on a large stage with all-star groups, presenting polished repertoire at ticketed concert events with limited seating capacity. During these intimate Facebook live settings, Corea shared his daily practice routines, unfinished pieces, works in progress, mistakes, and experiments, all the while interacting with frequent comments from listeners all over the world. For fans, it created a sense of entering into this master's personal space as an invited personal guest. This practice is an example of what Sarita M. Stewart described in her 2013 dissertation as the Artist-Fan- 
Engagement Model (1), a main driver for consumption and purchase decisions. This model requires para-social interaction, defined by Horton and Wohl as the illusion of face-to-face interaction through mass media (215). The close view of Corea's intimate practice spacecombined with the option of sending personal comments in real time-facilitated para-social relationships that translated into Academy subscribers.

2) Tamir Hendelman presents weekly Saturday solo piano concerts for paid ticket holders on Zoom. Each concert is themed with historical commentary and attended by 20-30 visitors for $\$ 20$ tickets, while additional concerts with special guests are offered at higher ticket prices. Hendelman is in high demand as a side-person and also leads his own groups. He usually tours worldwide several months a year and teaches at the University of Southern California. His wife, Sherry Luchette, is a bassist and Elementary Music specialist. In response to the shock of summer tour cancellations, Hendelman and Luchette decided to present virtual house concerts, an online version of a practice they had previously conducted in their home with invited guests. The adaptation to the online setting took several stages of experimentation and refinement. For instance, rather than having the visual components of a complete room, online settings only provide a screen-size glimpse into the performer's space, thus making the immediate backdrop a crucial focal point. Clutter, pictures, and any distractions quickly had to be removed. Further, the audio heard in the room does not reflect what is transmitted through the streaming platform via microphones and the Internet. Luchette transitioned from the role of hostess and cook for the party to monitoring the upstairs computer for sound transmission, comments, and general tech surveillance. As many participants came back weekly, Hendelman realized that he needed to offer unique content every week and find new ways of engagement. The solution was themed concerts with advance request options and historical commentary between selections. In addition, Luchette found that listeners liked to come early to get in the mood for the show and also wanted to "hang out" after the concert, which led to the creation of unique playlists and visuals prior to and after the concert shared via Zoom. She also frequently performed with her husband during these concerts, something that was more difficult during in-person house concerts due to her hosting responsibilities.

3) Live from Emmet's Place is a free livestreamed Monday night series from the Harlem home of award-winning pianist Emmet Cohen, with Cohen and guests. Cohen was an early adopter of this digital model, having first livestreamed on March 23, alongside his musician neighbours, bassist Russell Hall and drummer Kyle Poole. He quickly branded the events with a flickering neon-light sign title page, a recurring time slot, and simultaneous broadcasts on several platforms. The initial shirt-and-tie attire and awkward positioning of phones quickly gave way to a casual living room view and high-quality camera setups. With access to many prominent performers in close proximity, this specific series was able to overcome geographic isolation issues for musicians and create a series of high-calibre, high-quality performances. The Monday night sessions average 70,000+ views on Facebook, with additional viewers on Instagram and YouTube Live. Furthermore, Cohen has a private subscription service that offers access to private concerts and unreleased recordings through tiered memberships. Various prominent funders support the musicians, tech needs, and additional costs.

4) The Montclair, New Jersey-based education program Jazz House Kids, led by vocalist Melissa Walker and bassist Christian McBride, presents a recurring livestreamed event called the Friday Night Listening Party through Zoom and Facebook. Selected with a specific theme, each program brings together prominent artists through Zoom to discuss their work and various listening examples that the artists suggest. Exclusivity is created by giving the first 100 listeners to sign up on Zoom the privilege to ask questions and interact with the panelists. The videos are deleted after a certain time period, thereby encouraging audiences to tune in live rather than 
watching later. The master class model and guided listening experience offer educational opportunities and avoid compromises due to sound/video quality or performer availability. Frequent reminders in the comments from the Jazz House personnel encouraging support and school enrollment help funnel the audience engagement towards sustaining the Jazz House as an organization.

5) Neo-Soul crossover artist Erykah Badu took the concept one step further and built her own platform that includes all elements of fan engagement in one space. Furthermore, with elaborate set-ups, multiple cameras, costume changes, light projections, and much more, she engages in an ongoing process of perfecting the online experience for both the performer and the audience. Rather than engaging in streaming as a substitute for the live experience, she is refining the process towards a new performance platform. In a recent interview with the New York Times, she welcomed the option of not spending eight months of the year on the road away from her three children. As she builds her new company, "Badubatron," as well as taking classes in coding and preparing a new apothecary line, she embodies the music-sector transformation that is taking place: "I enjoyed the moment when the audience and the artist become one living, breathing organism, when the band and I are locked in. I miss that synergy and energy between me and the audience. But I found a new way to express that, and it doesn't take its place. It just evolved to another place" (qtd. in Ryzik). Her comprehensive platform eliminates payments to subsidiaries and captures fans, payments, experiences, and data in one central destination. The performances include elaborate production and choreography and musical interaction but also allow for fan interaction by taking requests and providing commentary.

Livestreaming is not unique to the jazz community and has become an essential tool across all performing arts. One of the largest financial and popular successes was rapper Travis Scott performing through his own avatar in the game Fortnite. The animated set of the gaming platform with amazing lighting and backdrops allowed for a stadium-type setup and experience. ${ }^{2}$ The newfound popularity of the platform Twitch and the success of Scott's experiment point towards gaming spaces as an option for the venues of tomorrow. There is much room for experimentation, though, and the intimate interaction in a jazz performance in particular allows for further options to be discovered and implemented. These examples, above all, demonstrate the effectual entrepreneurship process as they build new options from available resources.

The fact that this pandemic happened now and not twenty years ago makes a big difference.

(Tamir Hendelman. Interview with the author, July 1, 2020)

The stability of teaching income, as documented in the survey results, can be attributed to fulltime positions at schools and universities, which, fortunately, did not terminate contracts (although many are experiencing salary and hiring freezes). All teaching moved online forcing instructors to learn new digital tools for teaching and leading ensembles in minimal time. The stress caused by the abrupt separation of ensembles, lessons, and courses-and the need to create new teaching methods and content in minimal time-was extraordinary. Nonetheless, available technology and support seminars quickly resulted in a vast number of effective, newly virtual teachers. Bassist Sherry Luchette, who teaches Elementary General Music and private bass students, noted that incorporating visuals, listening examples, and movement has been key for creating engagement and connections in a virtual world.

On March 17, 2020, Caleb Chapman, owner of the Utah-based Soundhouse program, one of the world's leading pre-college music programs, texted his business partner Andrew Surmani: "So much for my million-dollar dreams. We're fully down." The model for the past twenty-two years, based on the cycle of rehearse-record-perform-tour, was shattered. With encouragement 
and a growth mindset as a practicing jazz saxophonist, he jumped into action. The next text he sent read: "Call Me!!!!!!!!! We're back in business." Over the course of twelve hours, he mapped out a new business model for creating online bands with the option of being coached by worldclass musicians and with additional access to special master classes and backstage talks. Instead of being tied to the Utah locations, students could now participate from anywhere in the world. Even so, the latency issue that prevents simultaneous online performance has yet to be solved and remote rehearsals mean recording individual parts to be edited together. ${ }^{3}$

Surmani, however, points out the various advantages to virtual collaboration techniques, such as perfecting a part for recording and getting immediate visual feedback from watching the videos, getting personal feedback, and becoming proficient with recording hardware and software. ${ }^{4}$ In addition, the profit margin increased due to lower facility and personnel costs as well as higher tier enrollment options with world-renowned coaches and additional master class options. The Soundhouse Studio Program was implemented quickly, offering not only combo programs, but also expertise in sound recording, access to world-renowned coaches and music industry sessions and interviews, and college preparation sessions. In fact, the quick action of a leadership team trained in improvisation created the first exemplary program of its kind and a model for transforming music education. The Soundhouse leaders now offer consulting options on successful implementation of technology for teaching music in their EdTech platform and through a new consulting business.

\section{If you were not already an educator who was student-centered and your learning environment wasn't student-centered learning, then COVID screwed you up.}

(Lenora Zenzalai Helm. Interview with the author, July 2, 2020)

While online teaching has increased in popularity during the past decade, the forced switch to online teaching was received with apprehension from teachers and students alike. Rather than making virtual content delivery an option, online classes became a requirement, with some students lacking access and enthusiasm and some teachers lacking technology and pedagogical skills. Authentic experiential learning has been found essential for student success in online courses (Duncan and Barnett 373). This sense of community and social interaction is more difficult to achieve in a virtual setting with limited opportunity for social connections.

Lenora Zenzalai Helm, Assistant Professor at North Carolina Central University, teaches vocal ensemble and ear training courses and creates shared listening exercises as a method of social engagement in an online environment, rather than taking on the role of content provider. Similarly, Tamir Hendelman, Lecturer at the UCLA Herb Alpert School of Music, describes how he uses Zoom breakout rooms for group projects and even overcame the audio delay issue of virtual performance by connecting with FaceTime on the phone and Zoom on the computer simultaneously.

I had to buy a new camera, I had to buy connections for my Mac, I had to buy a new light . . you don't have those things on hand.

(Lenora Zenzalai Helm. Interview with the author, July 2, 2020)

Even with the knowledge and willingness to adapt to new technology, the confinement to individual homes created an uneven playing field of access to the needed tools and personnel. Some musicians were well-equipped with home studios and even musical partners, while others lacked instruments, recording tools, and bandmates in their personal space. Software and recording devices had the highest marks for new acquisitions from survey respondents: 91 $(42.5 \%)$ and $93(43.5 \%)$ respectively (Table 4 documents the acquisition activities for survey 
participants). On May 12, 2020 Forbes reported on retailer Sweetwater Sound in Fort Wayne, Indiana, indicating a $253 \%$ sales increase in USB microphones; $23-48 \%$ increases for audio recorders, interfaces, and patch bays; and 5000 new online customers per day (Howard).

The need for equipment to function in a virtual world is also a budgetary challenge confirmed by $60(28 \%)$ survey respondents, who indicated needing new gear but not being able to afford it. 172 respondents (80\%) reported increasing their technology skills, and 180 (84\%) reported being ready to implement more technology in their future work (see Table 5). Unfortunately, besides teaching - which is generating more than $\$ 500$ a week for 30 respondents (14\%) and between $\$ 100-500$ for 50 respondents (23\%)-there is minimal translation of these new technological endeavors into income streams. In fact, livestreaming, home recording, virtual collaborations, and composing/arranging generated no income for 180 respondents (85\%).

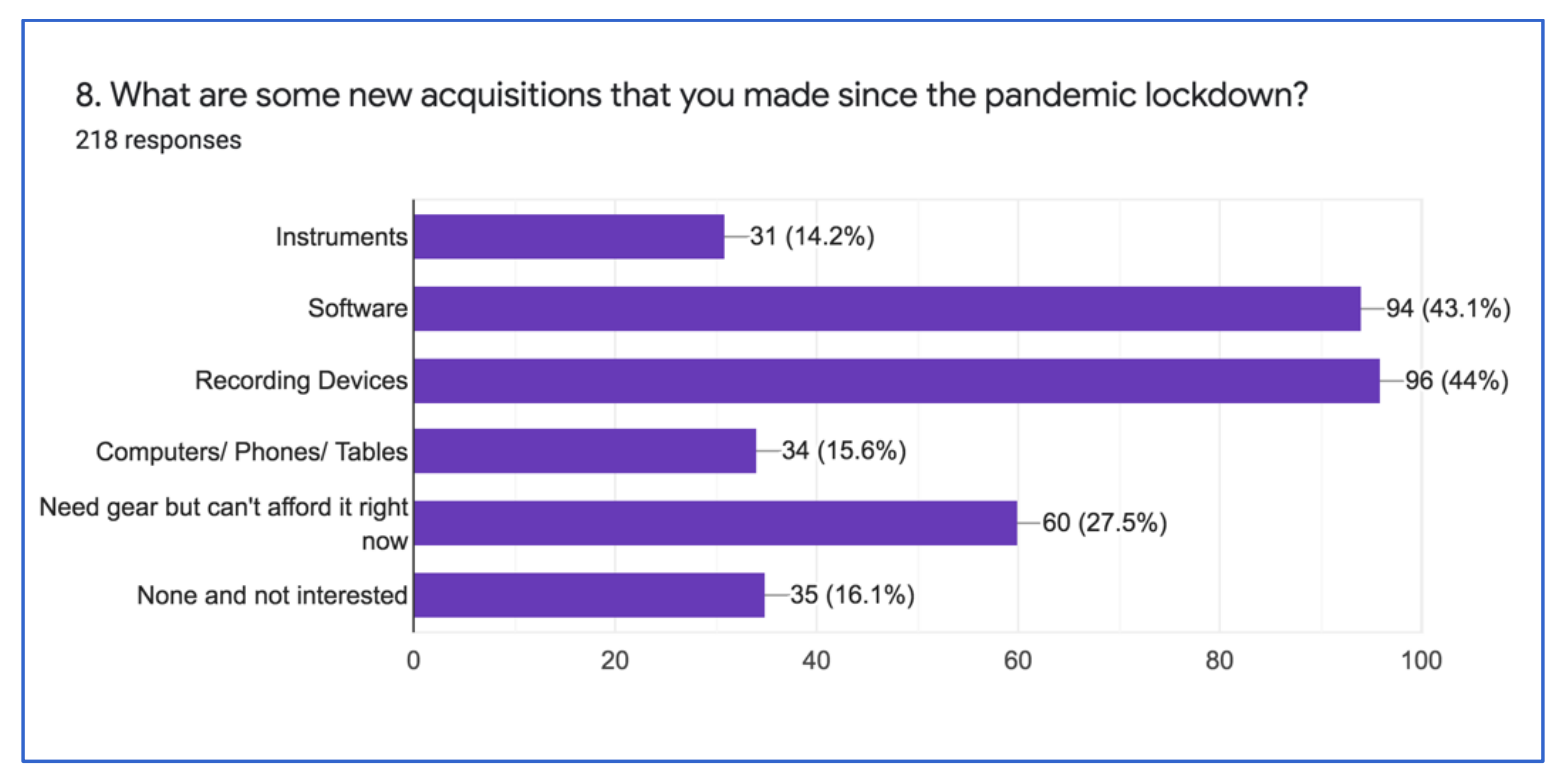

Table 4: New Technology Acquisition

I was just offered a job by the Miami Arts Charter to run their Music Tech program.

(Russ Spiegel, guitarist. Interview with the author, June 30, 2020)

The benefits of acquiring these new skills cannot be measured solely by the amount of income generated. The results are often new opportunities, expanded networks, or new forms of content creation. Guitarist Russ Spiegel led various elaborate virtual collaboration projects that required mastery of audio and video platforms, the latest of which included a complete orchestra with individual contributions by thirty-two musicians. The initial goal of the project was to provide content for a Patreon account and cater to monthly subscribers. Unfortunately, subscriptions at a \$5 monthly fee did not materialize (besides his fiancé), but the efforts resulted in several offers to teach music tech courses. Similarly, saxophonist Peter Lehel reported on the launch of a series of transcription videos that are attracting followers to his publishing work and record label, and Houston music educator José Antonio Díaz translated his new online pedagogy skills into the first Global Music Production \& Entrepreneurship Summit for young adults. Similarly, the Soundhouse Studio initiative resulted in the EdTech counselling start-up. As seen in Tables 5 and 6, the vast majority of survey respondents indicated learning in the area of music tech, especially in regard to online teaching, and there is general agreement that these newly acquired skills will be implemented in future work. 


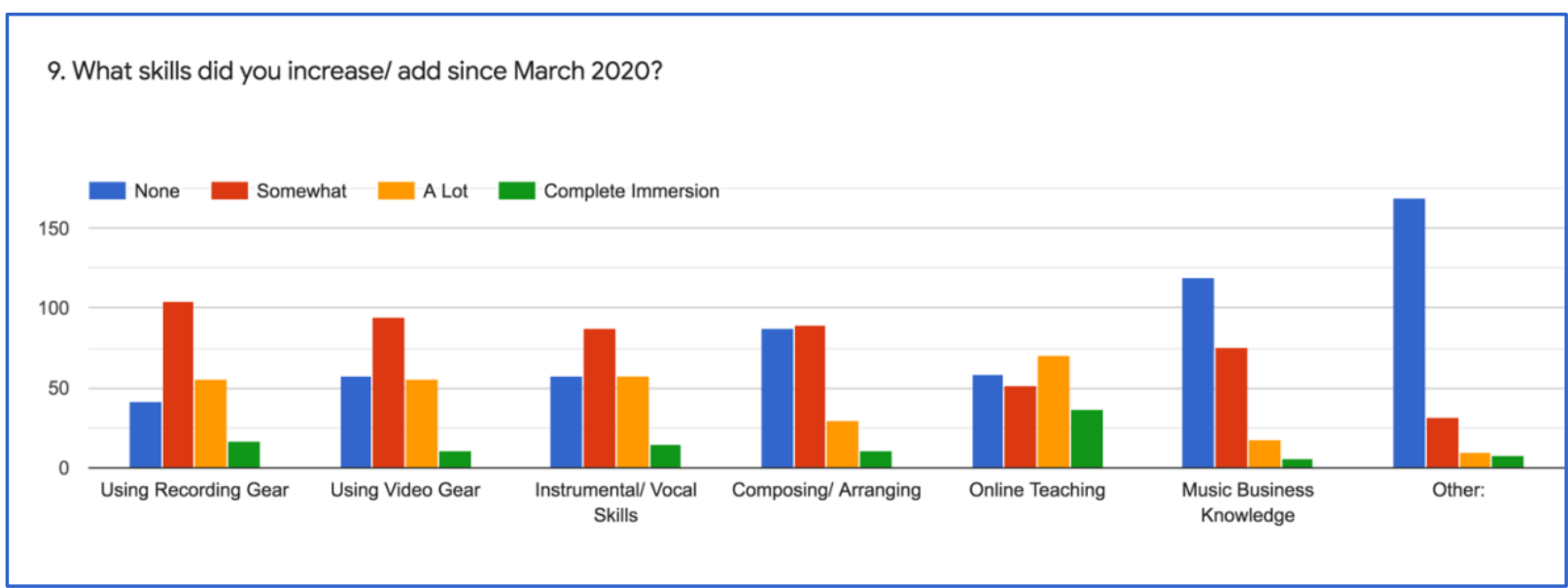

Table 5: New Skill Acquisitions.

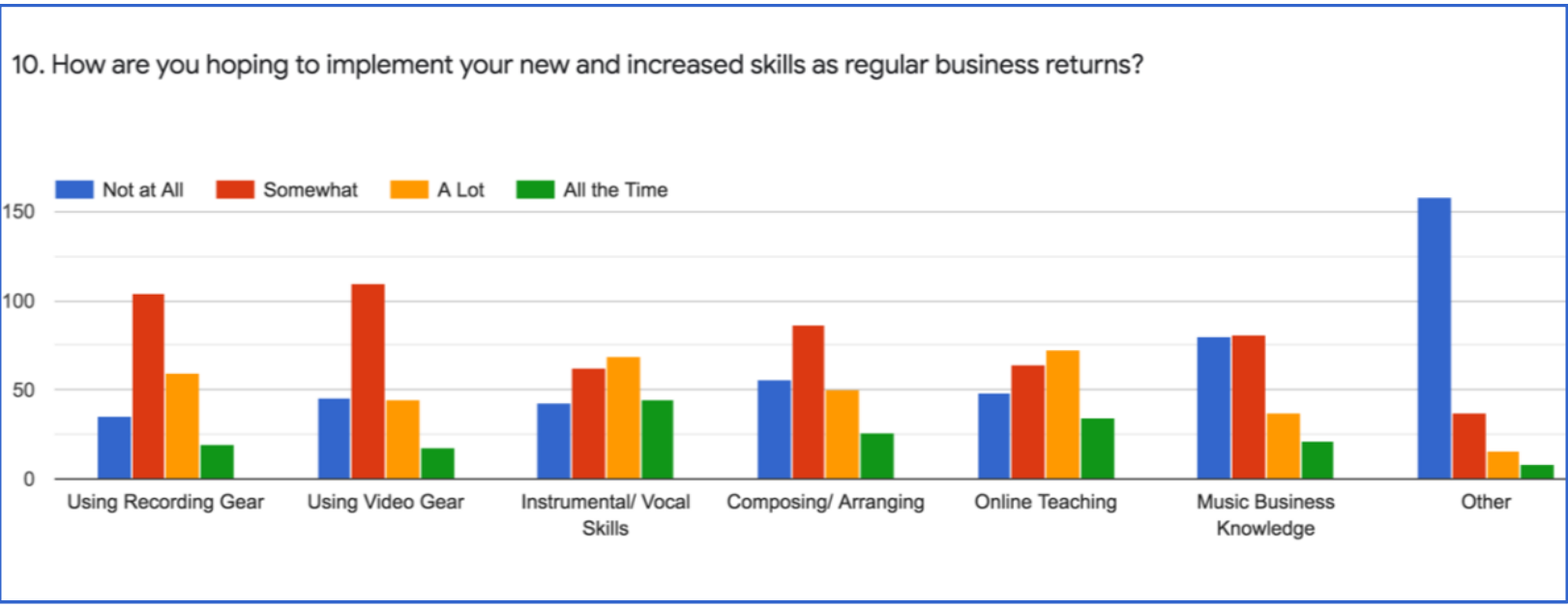

Table 6: Implementation of New Skills.

It's less expensive-l'm doing a bass camp next week. I don't need to travel with a big instrument; all I need to do is get a good kick in at home.

(Sherry Luchette. Interview with the author, July 1, 2020)

Even with the touring income lost and few new income streams, the equation also needs to include the travel costs saved, which include flights, hotels, meals, instrument rental and transport, gas, rental cars, touring personnel, and more. These expenses are substantial, as documented in the DiCola study, specifically the "Mythbusting" data memo (Thomson). On average, $80 \%$ of touring income is spent on expenses such as travel, salaries, and production, as documented in the jazz band leader case study (DiCola). And with many teaching camps, classes, seminars, and clinics going online for moderate fees-or for free-expenses for travel, housing, and meals are eliminated. It is not clear yet how online teaching compares in quality to in-person teaching, but the efficiencies in cost and time should be noted.

I need a second wave to get deeper into the music.

(Leni Stern. Interview with the author, July 8, 2020) 
Time is a gift. The disruption of busy teaching and touring schedules provided an opportunity to practice, learn new skills, write books and music, record with the help of technology and distance collaborations, hone music business skills, and spend time with families. 159 survey respondents $(74 \%)$ indicated that they used the time for increased musical practice and 129 $(60 \%)$ spent additional time composing and arranging music. Refining skills using audio and video recording technology became a priority for $173(80 \%)$ and $157(73 \%)$ respectively, and 97 respondents (45\%) indicated increased skills and knowledge in the music business area. Many commented on the opportunity to practice without time pressures and to be able to complete writing and composition projects. A special gift for many was the opportunity to spend extra time with children, a difficult balance for touring musicians. During the virtual Jazz Journalist Association broadcast, ${ }^{5}$ Male Vocalist of the Year winner Kurt Elling welcomed the extra time with his young son. In fact, the family decided to move back to Chicago after several years in New York to allow the children to grow up close to grandparents. Elling also emphasized the pressure of needing to create, be productive, and not feel like a failure to his dependents. Similar sentiments were expressed in the survey, indicating difficulties in sustaining a creative drive while moving forward into an uncertain future.

The really good thing about this is that we are able to provide work for more than 200 musicians, quite a few suppliers of technique [sic] and sound equipment, as well as restaurant [sic], bars and so on.

(Molde International Jazz Festival press release, July 2020)

The summer festival season turned into a series of cancellations including the Newport Jazz Festival, the Montreux Jazz Festival, the North Sea Jazz Festival, and most others. Some festivals found options to present on a smaller scale and with a focus on regional artists. In the case of the Molde International Jazz Festival, the original line-up of US stars Charles Lloyd, Cécile McLorin Salvant, Out of Land, Joel Ross, Makaya McCraven, Kurt Elling \& Danilo Pérez, and more could not be presented due to travel risks and restrictions. As a result, the complete program was restructured to feature Norway's leading artists in smaller and outdoor venues, following government safety guidelines.

German jazz musician Peter Lehel reported on the initiative of the city of Karlsruhe to present a paid series of livestreamed events with the condition that events include at least one local musician. Similarly, Smalls Jazz Club in New York presented daily livestreamed concerts supported by the Billy Joel Foundation, featuring New York combos. Similarly, neighbourhood events and outside concerts created by individuals and small communities provided income for regional artists and supported safe and joyful gatherings. The city of Ludwigshafen, Germany offered an adoption program to "rent" a musician for a personal concert. A renewed focus on local assets and recognition of local scenes is worth noting as another outcome of the pandemic.

\section{I want to move away from gig culture. I still enjoy jazz. But music has not created the stability I need as I age and experience medical emergencies.}

(Anonymous survey comment)

In spite of the creative solutions discussed earlier, the sudden loss of income and public performances with live audiences caused by COVID-19 elevated the shortcomings of the gig economy. Small businesses and freelance workers account for $20 \%$ of the US economy, but many will be unable to continue their profession due to their non-essential worker status, loss of income, and the economic instability of their work. Many respondents noted that the pandemic 
has revealed the precarity of life as working musician. Some have been able to sustain their careers with teaching jobs, other work, or by relying on their spouse's income, while others are switching careers entirely. Some musicians have succeeded in developing sufficient income streams from online content creation. The need to create a stronger infrastructure to support working musicians and to prevent similar setbacks in the future has never been more clear.

\section{Discussion}

On July 6, 2020 the National Independent Venue Association (NIVA) reported that, according to a survey of their members, $90 \%$ claimed they will close their doors permanently in a few months without federal funding (NIVA). At this point in time (Fall 2020), the shutdown of venues will most likely extend into the first half of 2021. The impact on the music industry and the economy in general is substantial. We find ourselves at a historic crossroads of loss and opportunity. This study found that, in large part, improvisers are leading us down the road of opportunity with a growth mindset by initiating effectual entrepreneurship. The quick reactions of some jazz musicians have resulted in a cycle of ideation, experimentation, and refinement of options in ways that build toward new strategies, directions, models, and solutions.

Live performance is a crucial element of jazz as an art form, but the heavy reliance on touring not only as an income stream but also as a marketing tool to sell products has created a lopsided system that collapsed easily when the crisis struck. The recording industry has traditionally relied on "album cycles," meaning artists record an album's worth of music that will enter a promotional chain of airplay and press reviews coupled with extensive touring in order to sell the music and increase fan interaction. Most of the revenue from album sales goes to labels and intermediaries while artists rely heavily on revenue from live performances. With the sharp decline of album sales and the option of releasing music continuously (or, at least, outside of the traditional album cycle model), content creation and marketing approaches can be restructured from the ground up. Being released from the sales demands of corporations, the grind of road trips, extended time away from family and loved ones, mounting travel costs, and countless hours of booking, musicians can creatively restructure their time. As noted in the introduction, the entrepreneurship literature identifies improvisational activity as a method to make decisions in uncertain situations. The new methods of virtual engagement that musicians have been developing during the pandemic have outlined a path towards a more sustainable future in which hybrid models involving both live performance and online activities may well become the norm.

That said, finding new performance models is not as easy as substituting a gig with a livestreamed concert. In fact, many attempts to do so will fail. On any given day, there are thousands of livestreams available across many platforms - the choices are endless. Mary Ivanova, Content and PR Manager at Show4me Music Interaction Network, recently published survey results analyzing the online experience of audiences. The most popular concern was lack of energy. Being at home without a stage, large band, and audience often lures the performer into a laid-back attitude and relaxed performance style that is noticeable to the virtual audience. Technical issues are also a common problem. Low quality audio and video as well as Internet and platform issues interfere with the experience no matter the proficiency of the musicians. Audiences prefer interactive elements. The physical distance can be overcome with comments, reactions, and acknowledging a shared experience. The banter should not get out of hand though, as the common experience is still the music, and extensive monologues result in audiences logging off. 
While jazz musicians have engaged in various types of livestreaming in order to connect to audiences, their efforts have not translated into substantial income streams and, according to research by Stanford University economy professor Nicholas Bloom, working from home-while potentially more productive-results in less creative output. Inspiration in the workplace comes from random conversations in the hallways and accidental meetings in the cafeteria; problems are solved more effectively with people being together in the same room.

Clearly, live performance with human interaction between band members and audiences is an essential element for creating and learning. Nevertheless, the opportunities to build repertoire and engage audiences are certainly available through livestreaming, and the task is to convert attention into engagement. The examples provided earlier illustrate the implementation steps needed to find the ideal format, platform, and level of interaction required for musicians to capture fan engagement in sustainable and artistically rewarding ways. One size does not fit all, and it takes improvisational tactics, experimentation, and, most of all, a vision and goals in order to find the ideal platforms, models, content, and tech setups. When Chick Corea opened his daily practice studio, he developed an audience base with the goal of preparing the launch of his academy, a new artistic venture that presumably would have allowed him to scale back touring activity had he lived beyond the pandemic. Emmet Cohen creates excitement and interest on many platforms, which translates into monthly paid subscriptions and sponsorships through his website. The listening parties hosted by the Jazz House Kids support their educational mission through the format of educational and entertaining master classes.

The adaptions and strategies developed in the jazz community provide valuable clues towards the shape of things to come. There are several commonalities among the improvised responses to the pandemic surveyed for the present study:

a. Livestreaming is not a substitute for live performance. New technologies don't replace operations, but they do increase the options. Rather than simply offering a live performance with audiences watching from somewhere else, virtual presentations offer an option for authentic engagement and intimate sharing of a variety of content.

b. Audiences respond to authenticity, uniqueness, good presentation quality, interactive elements, and strong content. The success of Caleb Chapman's Soundhouse Studio program was largely based on working with experienced teachers, using quality software and hardware, and maximizing interactivity.

c. Virtual engagement is a process of learning and experimentation, just like learning to work with live audiences. Feedback, observations, and comments help refine the presentation and content. The evolution and quick response of Emmet Cohen's presentations to audience reactions and sponsorship opportunities demonstrate his entrepreneurial approach.

d. Forms of engagement that lead to long-term bonds are the basis of sustainable ventures. Audience engagement needs to be funneled towards subscription options, investment values, and repeat encounters. Chick Corea's creation of the subscription-based academy is one example, as are the donation options foregrounded in the Jazz House Kids school's master class events.

e. The creative process is a democratic and shared experience. Instruments and music-making technologies are becoming easier to access, and the line between artists and audiences is increasingly blurry. The observed increase in creative output, learning of new musical skills, acquiring new instruments, and developing 
production skills is substantial. Nurtured by improvisational tactics, we're witnessing a new model of collaborative music making across geographic, cultural, and genre boundaries.

Proficiency in technology and access to equipment have become essential in all areas-from performing to teaching to recording to composing/arranging. But the need to learn skills quickly and buy gear during a time of scarce resources and high anxiety has created an uneven playing field. Differences were further amplified by shipping delays, supply shortages, and uneven access to high-speed Internet. Policy and governance are needed to provide equal opportunities that offer fair access to resources and expertise. As discussed earlier, there are essential flaws in the system and the support structure for artists and the burden of constantly finding industrious solutions should not rest solely on the shoulders of the artists; rather, it should be supported by institutions.

Such institutional efforts should focus on restoring communities from the inside out. Similar to the example of the Molde International Jazz Festival, there is an opportunity to practice restorative economics within communities. Limited travel options and physical distancing needs allow for a new recognition of available community assets, rather than the superstar economy. Examples are porch concerts, small outside festivals with local artists and workers, and similar initiatives to support and recognize local arts and businesses and to build a strong community. The profit margins of the previous touring model are small given the extensive labour, travel, and time costs. Technology makes connections and collaborations possible from any location, but investment in local communities frees up time and resources for creators. The improvised solutions epitomized by the Molde International Jazz Festival point towards a hybrid model of utilizing both local community and virtual connection resources.

"The show must go on" is the traditional motto of the entertainment industry and has certainly been apparent in the quick and varied responses of creators during COVID-19. One thing to look forward to in the wake of this pandemic are the large amounts of new music written and recorded that will express the emotions and social changes during this time. Created with few commercial pressures, these cultural goods will document the crisis and support the healing process. The sheer resilience of the improvising community is exemplary and inspirational and, based on the results of this study, will lead the way forward.

\section{Conclusion}

In 1906, John Philip Sousa warned of the "weakening throat" and the decline in music-making due to the spread of machines, recorded music, and other such disruptive technologies (Sousa 281). These doomsday alarms have rung regularly with the advent of new technologies throughout history. Being suddenly thrown into a pool of cold water, the choices are to sink or learn to swim. There is a chorus of voices asking to go back to a pre-COVID world, declaring livestreaming inferior to live performance, calling online teaching ineffective, and lamenting the loss of selling music. It is reminiscent of the band that, devoted to their routine, keeps playing while the Titanic sinks. By contrast, for those willing to audition and practice their parts, there is an opportunity to join a new orchestra, one rehearsing a new repertoire that expresses the current artistic, social, and emotional land- and soundscape. There is also an opportunity to escape a broken system of serving as a marketing object for corporate sales. Yes, as a survey respondent put it, "we miss the gigs, the music, the vibe, the beers, the friends, the audiences. We miss being out on the road and sharing the experience." On the other hand, another respondent points out: "I do think that this forced creativity is allowing people to be clever about embracing new approaches to add to their artistic tools." 
Now that the former model has shattered, there is no need to put the pieces back together. Rather, we have an opportunity to create a new mosaic that will foster musical creativity and community. For it to be an effective and sustainable support system, it has to be a communal, institutionally-supported effort. What we can observe in the improvising community are resilience, a growth mindset, and effectual entrepreneurship towards new models, but we can't put the burden of implementing a new system on the shoulders of artists. While Sousa feared that the mechanical device would become a "substitute for human skill, intelligence, and soul," (Sousa 278) we now have the opportunity to integrate the mechanical device to further human skill, intelligence, and soul. Even though the CD release tour for my group, Sheroes, came to a screeching halt in March 2020, our album Eternal Dance soared into the JazzWeek airplay charts, landing at number six and staying in the Top 50 for 16 weeks. All the while, the group is collaborating virtually on various projects despite geographic separation. Now that the traditional tour and album cycle is broken, the options are endless.

\section{Notes}

${ }^{1}$ See soundcharts.com/blog/music-streaming-rates-payouts.

${ }^{2}$ Watch the performance here: https://www.billboard.com/articles/columns/hiphop/9361811/travis-scott-fortnite-astronomical/.

${ }^{3}$ Latency refers to the amount of time it takes for a sound signal to travel from one location to the other causing problems for musicians to sync up to the same timing. Hence, students record their parts and send in the tracks to be edited together in audio software.

${ }^{4}$ Interview with Andrew Surmani via Zoom, July 13, 2020.

${ }^{5}$ See youtu.be/KbU57wMeVes.

\section{Works Cited}

"2020 Jazz Journalist Awards Winners Live-Streaming Party, Archival Edition." YouTube, uploaded by “Jazz Journalists," 26 June 2020, https://youtu.be/KbU57wMeVes.

Barrett, Frank J. "Managing and improvising: Lessons from jazz." Career Development International, 1998.

Belitski, Maksim, and Monika Herzig. "The Jam Session Model for Group Creativity and Innovative Technology." The Journal of Technology Transfer, vol. 43, no. 2, 2018, pp. 506-21.

Diasio, Steve. "Not All that Jazz! Jamband as a Metaphor for Organizing New Models of Innovation." European Management Journal, vol. 34, no. 2, 2016, pp. 125-34.

DiCola, Peter. "Money from Music: Survey Evidence on Musicians' Revenue and Lessons about Copyright Incentives." Arizona Literature Review, vol. 55, 2013, p. 301.

Duncan, Heather E., and John Barnett. "Learning to Teach Online: What Works for Pre-Service Teachers." Journal of Educational Computing Research, vol. 40, no. 3, 2009, pp. 35776. 
Duxbury, Tom. "Improvising entrepreneurship." Technology Innovation Management Review, vol. 4, no. 7, 2014.

Eisenhardt, Kathleen M. "Strategic Decision Making as Improvisation." Strategic Decisions. Boston: Springer, 1997, pp. 251-57.

Hatch, Mary Jo. "The Jazz Metaphor for Organizing: Historical and Performative Aspects." Critical Management Studies, Popular Culture and Critical Management Stream, 1999, pp. 1-17.

Herzig, Monika, and David Baker. "Beyond Jamming: A Historical and Analytical Perspective on the Creative Process." MEIEA Journal, vol. 14, no. 1, 2014.

Horton, Donald, and R. Richard Wohl. "Mass Communication and Para-Social Interaction: Observations on Intimacy at a Distance." Psychiatry, vol. 19, no. 3, 1956, pp. 215-29.

Howard, George. "Sales of Recording Gear Are Soaring During COVID-19. Just Ask Sweetwater's CEO." Forbes, 12 May 2020, www.forbes.com/sites/georgehoward/2020/05/12/sales-of-recording-gear-are-soaringduring-covid-19-just-ask-sweetwaters-ceo/\#1010151573bf.

Ivanova, Mary. "What Fans Think of Online Concerts and How to Improve Them." Hypebot, http://www.hypebot.com/hypebot/2020/07/what-fans-think-of-online-concerts-and-howto-improve-them.html. Accessed 21 Apr. 2021.

Kamoche, Ken, and Miguel Pina E. Cunha. "Minimal Structures: From Jazz Improvisation to Product Innovation." Organization Studies, vol. 22, no. 5, 2001, pp. 733-64.

Lamarre, Carl. "Travis Scott Partners with 'Fortnite' for New In-Game Concert 'Astronomical': Watch the Full Video." Billboard, 25 Apr. 2020, https://www.billboard.com/articles/columns/hip-hop/9361811/travis-scott-fortniteastronomical/.

Lewin, Arie Y. "Introduction—Jazz Improvisation as a Metaphor for Organization Theory." Organization Science, vol. 9, no. 5, 1998, p. 539.

Limb, Charles J., and Allen R. Braun. "Neural Substrates of Spontaneous Musical Performance: An fMRI Study of Jazz Improvisation." PLoS One, vol. 3, no. 2, 2008.

Mendonça, David J., and William A. Wallace. "A Cognitive Model of Improvisation in Emergency Management." IEEE Transactions on Systems, Man, and Cybernetics, Part A: Systems and Humans, vol. 37, no. 4, 2007, pp. 547-61.

"Molde International Jazz Festival 60 ${ }^{\text {th }}$ Anniversary." Europe Jazz Network, https://www.europejazz.net/news/molde-international-jazz-festival-60th-anniversary. Accessed 21 Apr. 2021.

Moorman, Christine, and Anne S. Miner. "Organizational Improvisation and Organizational Memory." Academy of Management Review, vol. 23, no. 4, 1998, pp. 698-723.

Nielsen Music. "Mid-year report: U.S. 2020." 2020, 
static.billboard.com/files/2020/07/NielsenMID-YEAR-2020-us-1594300786.pdf.

NIVA (National Independent Venue Association). "NIVA Policy and Fact Sheet." 7 July 2020. static1.squarespace.com/static/5e91157c96fe495a4baf48f2/t/5f05072d32e6e2237f9fb94 0/1594165037291/NIVA-+Policy+and+Fact+Sheet.pdf.

Pastukhov, Dmitry. "What Music Streaming Services Pay Per Stream (And Why It Actually Doesn't Matter)." Soundcharts Blog, 26 June 2019, https://soundcharts.com/blog/musicstreaming-rates-payouts.

Ryzik, Melena. "Erykah Badu Is Blazing a New Trail (From Badubotron)." The New York Times, 21 July 2020, https://www.nytimes.com/2020/07/21/arts/music/erykah-badulivestreams.html.

Sarasvathy, Saras D. "Effectual Reasoning in Entrepreneurial Decision Making: Existence and Bounds." Academy of Management Proceedings. Briarcliff Manor, NY 10510: Academy of Management, 2001.

Sousa, John Philip. “The Menace of Mechanical Music.” Appleton’s Magazine, vol. 8, no. 3, 1906, pp. 278-84.

Stewart, Sarita Martin. Artist-Fan Engagement Model: Implications for Music Consumption and the Music Industry. 2013. University of Alabama, PhD dissertation.

Thomson, Kristen. "Mythbusting: Data Driven Answers to Four Common Assumptions About How Musicians Make Money." Future of Music Coalition, 2 Dec. 2012, http://money.futureofmusic.org/mythbusting/3/.

Vera, Dusya, et al. "Knowledge-Based and Contextual Factors Associated with R\&D Teams' Improvisation Capability." Journal of Management, vol. 42, no. 7, 2016, pp. 1874-1903.

Walzer, Nana, and Andreas Salcher. "Management by Jazz - Creating Innovation from the Principles of Chaos and Order." Industrial and Commercial Training, vol. 35, no. 2, 2003, pp. 67-69.

Weick, Karl E. "Introductory Essay: Improvisation as a Mindset for Organizational Analysis." Organization Science, vol. 9, no. 5, 1998, pp. 543-55.

Zack, Michael H. "Jazz Improvisation and Organizing: Once More from the Top." Organization Science, vol. 11, no. 2, 2000, pp. 227-34. 